\title{
Investigation of Community Perceptions of a New Higher Education Institute in Rural Rwanda
}

\author{
By Claire Kimilu, Diana Rujema, Joseph Kalibbala, Jenae Logan \\ \& Rex Wong \\ University of Global Health Equity, Rwanda
}

Abstract- Background: The community perceptions, experiences, and expectations concerning a new rural university were examined to give insight into the role of higher education institutions in optimizing positive community engagement and social development in rural contexts.

Methods: Five focus group discussions were conducted with community members.

Results: While most participants acknowledged UGHE as an educational institution focusing on the delivery of medical care within rural and vulnerable settings and expressed pride, they also perceived UGHE as a foreign and expensive institution and were uncertain of financial implications. Those displaced by campus construction also felt exploited. Participants did not have accurate information about the university and generally welcome more interactions.

Keywords: higher education institute, community engagement, rural, Rwanda, community service.

GJMBR-A Classification: JEL Code: L26

Strictly as per the compliance and regulations of:

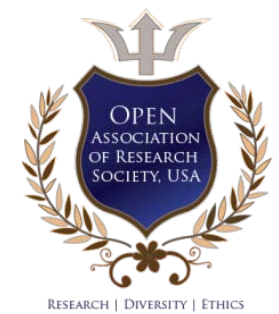

(C) 2020. Claire Kimilu, Diana Rujema, Joseph Kalibbala, Jenae Logan \& Rex Wong. This is a research/review paper, distributed under the terms of the Creative Commons Attribution-Noncommercial 3.0 Unported License http://creativecommons.org/licenses/by-nc/3.0/), permitting all non-commercial use, distribution, and reproduction in any medium, provided the original work is properly cited. 


\title{
Investigation of Community Perceptions of a New Higher Education Institute in Rural Rwanda
}

\author{
Claire Kimilu ${ }^{\alpha}$, Diana Rujema ${ }^{\sigma}$, Joseph Kalibbala ${ }^{\circ}$, Jenae Logan $^{\omega} \&$ Rex Wong ${ }^{*}$
}

\begin{abstract}
Background: The community perceptions, experiences, and expectations concerning a new rural university were examined to give insight into the role of higher education institutions in optimizing positive community engagement and social development in rural contexts.

Methods: Five focus group discussions were conducted with community members.

Results: While most participants acknowledged UGHE as an educational institution focusing on the delivery of medical care within rural and vulnerable settings and expressed pride, they also perceived UGHE as a foreign and expensive institution and were uncertain of financial implications. Those displaced by campus construction also felt exploited. Participants did not have accurate information about the university and generally welcome more interactions.
\end{abstract}

Conclusion: Residents expressed interest in health education, income-generating initiatives, and local employment. Formation of a community advisory committee with continued intentional interactions with community members can open communication channels to improve awareness of UGHE's mission and further strengthen the relationship.

Keywords: higher education institute, community engagement, rural, Rwanda, community service.

\section{BACKGROUND}

n a global era, higher education institutions (HEls) are situated to serve as catalysts of social transformation. HEls have assumed increased responsibilities to stimulate social and economic development when located within rural and developing communities (Thompson, 2014). Some rural-based universities have dedicated themselves to empower and build capacity among local community members, alleviate poverty, and reshape rural environments (Luvalo, 2014). Involving locals throughout each stage of project development and implementation, these universities emphasize community-engagement as a critical factor in achieving sustainable development. Increased interest in global health has expanded the role of HEls in global development. Through medical education partnerships, many universities of the Global

Author $\alpha \sigma \rho$ : Graduate student, University of Global Health Equity, Rwanda. e-mails: ccecilia014@gmail.com, rujemad@gmail.com, josephkalibbala@gmail.com

Author w: Director, Executive Education, University of Global Health Equity, Rwanda. e-mail: Jlogan@ughe.org

Author ¥: Director, Bill and Joyce Cumming's Institute of Global Health, University of Global Health Equity, Rwanda; Lecturer, Yale University, USA. e-mail: rwong@ughe.org
North and South now collaborate to improve the wellbeing of people and the planet through education, research, service, and advocacy (CUGH, 2019; Taché, 2008; Cancedda, Cotton, Shema, Rulisa, Riviello, et al, 2018; Binagwaho, Kyamanywa, Farmer, Nuthulaganti, Umubyeyi, Nyemazi, et al, 2013; Crane, 2010; Kolars, 2012). Global partnerships have been enhanced by the Consortium of Universities for Global Health (CUGH) which unites a network of 185 academic institutions and global organizations (CUGH, 2019).

While newly-developed institutional partnerships provide opportunities for cross-cultural collaboration and innovative social development, challenges remain in ensuring equitable collaboration and mutual benefit among resource-rich and resource-limited partners (Crane, 2010; Taché, 2008). Recent research has found successful sustainable development requires three key factors: 1) perceived ownership by Sub-Saharan African partners, 2) continued communication among leaders, and 3) a focus on building local expertise (Kolars, 2012). These factors can be extended to the local community partnerships underlying broader global partnerships (Mtawa, 2016).

While the idea of community service ("community engagement") is becoming a tradition within higher education, its definition varies among HEls within different regions and academic disciplines (Mtawa, 2016; CHE, 2004). In its most recent understanding, community engagement is embedded within the process of knowledge exchange; universities and communities are partners in inquiry, learning, and application of new knowledge (Mtawa, 2016). Little research exists regarding this concept of "scholarship of engagement" within Sub-Saharan Africa. Limited understanding of community engagement within higher education contributes to knowledge gaps concerning effective methods of community-engagement and best practices for joint-development. In global health, which emphasizes equitable partnerships for sustainable progress, there is critical need to understand local communities' perceptions and experiences of development especially within the Global South.

With a unique curriculum rooted in the "scholarship of engagement," the University of Global Health Equity (UGHE) is pioneering a new approach where higher education fuels social development. Opening its first permanent campus in 2019 in the rural community of Butaro, Rwanda, UGHE aims to equip 
students with experiences and skills to "protect the most vulnerable and improve health outcomes and social systems" (UGHE, 2019). Considering the continued discourse surrounding community engagement within higher education, we undertook this study to examine a developing partnership between UGHE and Butaro community. Laying a foundation for UGHE's successful integration and community engagement initiatives, this study aimed to expand our understanding of community perceptions, experiences, and expectations concerning UGHE and its mission to contribute to social development. The results of this study can promote positive outcomes for UGHE development initiatives. As the establishment of HEls within rural communities remains a novel phenomenon in global health and development, this study further contributes to a body of knowledge concerning the role of HEls in global health and social development. It offers insight into effective means of social integration and community engagement in the context of rural-based educational institutions.

\section{Methods}

\section{a) Setting}

This study was conducted in Butaro Sector, Burera District, Northern Province, Rwanda, where the common language spoken is Kinyarwanda. Butaro is the second most populated sector in Burera District, with a population of 31,520 (Ndayisaba, 2019). Among the 8,255 households, 81 were relocated for the construction of UGHE campus (Ndayisaba, 2019). The community is served by sixteen nursery schools, nine primary schools, five secondary schools, and one vocational institution, all owned or aided by the government (Ndayisaba, 2019). UGHE is the only university in the sector.

Agriculture is Butaro's major economic activity with $99.5 \%$ of the population relying on subsistence farming (The Republic of Rwanda, 2012). Health infrastructure, access to healthcare, human resources for health $(\mathrm{HRH})$ and hygiene and sanitation practices are some key health concerns in the area. Many nongovernmental organizations (NGOs) and local agriculture and livestock organizations operate in the area (Ndayisaba, 2019). As of 2012, Butaro hosted approximately 76 foreigners (The Republic of Rwanda, 2012). This number is believed to have increased with the establishment of Butaro Hospital and UGHE's Butaro campus.

\section{b) Study design and sample}

A qualitative study using five focus group discussions (FGD) consisting of six to eight participants each was conducted in May through July 2019. One FGD consisted of Butaro town residents including local business people. Two FGDs consisted of residents who were displaced from university land. One FGD consisted of local staff at UGHE-cleaners, security guards, kitchen staff, construction staff, and landscape workers. The fifth FGD consisted of local leaders in Butaro sector-village leaders, community health workers (CHWs), heads of social services, and gender officers.

Community participants were selected via purposive and snowball sampling. Local leaders and community members who had pre-established relationships with the university and/or researchers gave referrals for participants. Participants for the local staff FGD were selected via convenience sampling.

Participants were 18 years and older. Participants were excluded if they had lived in Butaro for less than six months or had any mental disabilities which prevented them from fully understanding FGD information or from providing informed consent.

\section{c) Data collection tools and procedures}

Semi-structured focus group guides (Appendix 1) were developed with questions related to community perceptions, social integration, and global health within higher education. The questions varied slightly based on the focus group memberships. Questions for Butaro residents and local leaders focused more on UGHE's development, while questions for residents displaced by UGHE's construction focused more on their personal experiences. Guides were translated from English to Kinyarwanda with the assistance of hired translators. Translated guides were modified based on feedback from pre-testing with Kinyarwanda-speaking UGHE students and staff.

With the exception of the local UGHE staff FGD, all FGDs were conducted at a location within the community of the group's choosing to account for perceived power imbalances. The local UGHE staff FGD was conducted on campus out of convenience for participants. Written consents were signed by each participant after the research team explained the purpose of the study and the consent process. A skilled moderator facilitated discussions in Kinyarwanda per the preference of participants using the translated focus group guide. All participants were encouraged to contribute. Prior to FGDs, the moderator was trained on the study's purpose and objectives and offered time to familiarize himself with and discuss any questions he had about the FGD guides. All FGDs were audio recorded (with consent from study participants) and lasted approximately ninety minutes. All participation was voluntary and no stipend was provided to study participants.

The study was approved by the Institutional Review Board (IRB) of UGHE and by Butaro Sector leaders.

\section{b) Data management and analysis}

Audio recordings were transcribed in Kinyarwanda and then translated to English by an 
experienced translator fluent in both languages. The translator also acted as the facilitator for FGDs to ensure an accurate understanding of participant responses and the validity of translations.

Each transcript was independently coded by three researchers using inductive coding. A final codebook was developed after thorough discussion and agreement among researchers. All transcripts were recoded using qualitative data analysis software Dedoose for final analysis. All codes were subsequently organized into categories, then emerging themes.

\section{Results}

A total of 39 Butaro residents participated in five focus group discussions. Analysis of transcripts yielded 45 codes, 11 categories, and four themes to describe participants' understanding, interactions, attitudes, and expectations of UGHE.

a) Understanding of UGHE

Most participants acknowledged UGHE as an educational institution focusing on the delivery of medical care within rural and vulnerable settings: "I know this university is a medical institution working with [Butaro] hospital and with us" (Displaced resident); "the university prepares students in the field of medicine. Medicine for all the people in the world, especially in rural areas"(Town resident). Some described UGHE as a university which trains aspiring health professionals to practice in rural or underserved areas around the world: "Its [the university's] primary goal is to educate about health and to take care of patients in and out of the country. The students who will graduate from it or studying in it will be the ones to deliver that assistance here or abroad" (Local UGHE staff).

While they understood UGHE is a higher education institute, most participants perceived it as expensive, foreign, out of their reach, inaccessible to, and separated from the local community: "it is an expensive university... no Rwandan or anyone living here can afford to study in it according to the fees required" (Local leader). Some thought the university was predominantly run by expatriates and catered to international students: "We hear that only foreigners are studying there" (Displaced resident).

b) Interactions with UGHE

The respondents' interactions with UGHE ranged from none, transactional and service-based, to social interactions.

Some participants had limited or no interaction with UGHE students, staff, and faculty: "I have not yet reached there [the university], I do not know the director of the campus, I do not know the students except I see them on the road and in cars" (Displaced resident). They perceived the University had not formally visited the local community: "We often see university students walking around Butaro but university authorities should visit the community and converse with them as well as introducing themse/ves" (Displaced resident). Some even described participating in the focus group discussion as "my first time to meet [UGHE students]" (Town resident).

Some participants described their interactions with UGHE as service-based. This meant either conducting business with or providing services to the UGHE students and staff: "I assisted two students from the university who were applying for short-term visitor's visa for Congo and Burundi ... I helped some who were applying for the [UGHE] security job in credential-related services too" (Town resident); "when the university was still under construction, some of the [UGHE] employees used to bring their children to my nursery; others also rented my houses" (Town resident). Such service-based interaction was positively perceived by the participants: "I have a barbershop/salon. They [UGHE employees] come and we serve them, hence I gain new customers" (Town resident).

Social activities were a major pathway for regular interaction among UGHE and the local community. Participants described their interactions with students and staff during social events within the community including church, sports events, and Community Laboring Saturday (known as Umuganda). They mostly saw this kind of interaction as positive: "we met both the staff and students from UGHE at Community Laboring Saturday. We were happy to see students and staff familiarizing with us. This improves our relationship and work together for the development of all" (Local leader); "I was happy to see [UGHE] coming and having a [football] match with the youth from Butaro" (Local leader). Some participants saw UGHE participation in social events as a positive respect to their community: "We have been together with university students during the Genocide Commemoration Week. Their lecturers also marched with us in the 'Walk to Remember'" (Town resident).

\section{c) Attitudes about UGHE}

Participants expressed a range of attitudes towards UGHE, ranging from pride to fear to uncertainty.

Participants described a sense of pride during the early construction phases of UGHE. They were happy that UGHE is in their home (Butaro): "UGHE made us famous. We became famous in the world. Even people in America now know Butaro" (Local UGHE staff); "We're happy because the university was established in our cell and it creates a sense of pride for us. We were delighted" (Displaced resident); "[the university] was brought here to Butaro, a rural area. Bringing it here is making us popular because it came to Butaro, our home" (Displaced resident).

However, having an elite institution in their community also brought some negative perceptions. They perceived UGHE students and staff as superior in social status, power, and influence: "I was compensated 
for my land and came to live nearby. When the construction was finished, I went there to search for a job. They chased me away saying that they want people with degrees. They see us as unable people, yet we have the energy to work but they undermine us. I doubt that they will even pay attention to our suggestions if you advocate for us" (Displaced resident).

There were also enhanced notions of UGHE's financial inaccessibility: "[UGHE] keeps the expensive stuff inside the campus. I do not know how they get what they need daily or if their needed products are stored on the campus. They do not buy anything here in the surrounding community to develop people living in this neighborhood" (Displaced resident). Some participants also thought UGHE preferred outsourcing goods and services: "I thought they never eat food from here... their food came packaged and were consumed within the university"; "We do not even sell UGHE what they need. We want them to buy from us. We are like two separate countries. them and us" (Local leader).

Some participants expressed feelings of exploitation, especially those displaced by the construction: "we do not see any other important impact on us since our children cannot study there. We give them land and then disappear" (Displaced resident); "We thought the university would be important to us. We gave out our land happily. But after the construction, they showed us that they are bad people" (Displaced resident). Some mentioned that "What UGHE wanted from us was the land and we left. Nothing else" (Displaced resident).

Participants also expressed feeling hopeless for their future following relocation and UGHE's presence in Butaro: "things will really worsen because if [UGHE] brings only foreigners because of high costs, none of our children can afford to study there because of our financial means. This implies that in the coming days,... people like us are not sure if they will continue to stay here because only graduates will be hired; and we will not be able to compete with them in the labor market" (Displaced resident).

Participants also expressed their uncertainties. They were not sure how UGHE would benefit them. Some participants who own businesses mentioned that a lack of clear direction from the university did not allow them to plan for their business: "we keep asking whether all incoming students will stay in the campus, we cannot decide if we should build houses for renting. You can understand that uncertainty is one of the drawbacks we are facing as business people" (Town resident).For workers, uncertainty about their job stability was also a concern for them: "Until now there is no problem, we are well paid. But as time passes, cleaners like us don't know whether we will continue or not" (Local UGHE staff).

\section{d) Expectations of UGHE}

Participants described their expectations for development and overall standards of living within Butaro. Participants expressed UGHE's potential to drive growth and development within the community, mentioning new investments and innovations. They expected UGHE to boost the local economy and provide individuals with opportunities for new incomegenerating activities. Examples include selling farm produce to UGHE, establishing hotels/restaurants, investments in schools, and improved transport systems: "I am a farmer. If I know the university will be an assured market, that will improve my standard of living. If I sell them at a good price, I will get the school fees for my kid. They [the community] will build hotels and will bring more and more development activities. Many [people in the community] have already purchased land plots for many other projects following this university. Lives will be transformed" (Town resident).

Participants also expected the infrastructure brought by the university would benefit the community. The Rwandan government is constructing roads connecting Butaro to other towns due to the establishment of the university in Butaro: "After the road construction, many factors that will influence our development. With the construction of roads, trade activities from the vicinity will develop" (Local leader).

These expectations encompassed beliefs that UGHE's presence should contribute to improved health outcomes. Participants expressed a desire for UGHE to educate the local community in areas of health promotion: "What I wish from our relationship with the university is that they educate about health especially. I would suggest students plan time for community extension education in our village to teach about hygiene. It would be better" (Displaced resident); "I am not saying that we are malnourished but teaching us about a balanced diet will be helpful...also teaching people about preventing disease caused by poor hygiene" (Town resident).Apart from providing health education in the community, participants also expressed the desire for UGHE to help the local school in health education: "there is not even a nursery, primary or secondary school teaching health [in Butaro], so UGHE can educate them for instance about washing hands after using the toilet" (Local leader).

Reflecting on their experiences of minimal interaction and perceived isolation and elitism, participants suggested meaningful interaction as a pathway toward building more positive relationships with UGHE. They believed UGHE could form a strong relationship with the community: "Let [UGHE] come and teach so that we don't feel distant to them. We should even befriend [UGHE]"(Town resident). With a stronger relationship, the university will gain a better 
understanding of community needs: "Our ideal relationship with the university would be getting to know students and conversing when we meet so that we tell them what we think (like we are doing now)... and then hang out together. When you hang out with someone, you exchange ideas and give advice on how to improve your relationship" (Displaced resident); "Coming outside the campus and interacting with the community can benefit both of us. As we get to know each other would help people understand the impact of the university in their lives" (Town resident).

Participants also welcomed more interactions with UGHE so that the university is better situated to serve as an advocate for the community: "I would like to suggest that if possible, you would advocate for us, who are neighbors of the university" (Local leader).

Since some participants viewed the "elite" university as inaccessible, they expressed the desire to be allowed to see the inside of the university: "Our wish is that we meet frequently and visit each other so that we can be allowed to visit the university and have a look at the buildings for which we left our land" (Displaced resident).

\section{Discussion}

While global development efforts in rural communities are grounded in good intentions, unforeseen changes are sometimes inevitable (Fine, 2019). From the perspective of local leaders and business people, UGHE is considered an avenue of urbanization and an opportunity for economic growth and development, from improved roads and transport systems in the past to increased access to electricity and water in the future. For local staff members, UGHE is seen as an institution that improves the quality of life in Butaro through local employment. Perceptions of relocated residents, on the other hand, were mixed. They expressed dreams of what they could have accomplished with monetary compensation for their land and how their initial expectations have yet to be met. They quickly began to feel the growing pains of adjustment upon discovering their previous way of life did not necessarily fit into their new reality after relocation. Relocated residents highlighted unintended consequences as a "natural challenge of global development" (Fine, 2019). UGHE's social impact altered their way of living. Their adjustment woes prompted us to consider the concept of creative destruction-the social change that involves the replacement of old institutions, traditions, and previous ways of life with new ones (Fine, 2019). The worth of UGHE and other global development projects must hinge on their ability to positively impact the most vulnerable (Fine, 2019). UGHE and other development projects must continually: ask themselves whether local communities are included in their efforts to achieve progress; ensure human dignity is maintained; and constantly monitor the effects of well-intentioned development initiatives.

Butaro community members shared a common perception of UGHE as an "international" institution run by expatriates and catering to foreign students despite realities of UGHE's national ties and mission to build capacity among health care professionals within Africa. The Butaro community further distinguishes the institution, staff, and students based on socio-economic status. Even UGHE's Rwandese staff and students were viewed as "other" in relation to the local community. Physical barriers distinguishing university land, extravagant buildings, and heavily guarded gates which only open to large containers and "big white [coasters and SUVS] carrying foreign goods and people," as described by a local resident, all gave the perception of an inaccessible campus that was somehow "other."

Participants characterized UGHE students as affluent and the institution as "exclusive" believing that the average Butaro student could only dream of studying there. Such perceptions present a common challenge to successful community engagement and ultimately social integration among HEls (Bender, 2008).

Local leaders and local business people seem to have a more accurate understanding of UGHE's purpose and operation within Butaro and more positive outlook about UGHE's impact on the local community. Conversely, testimonies of displaced residents seem riddled with confusion and hints of miscommunication which elicit frustration, unrealistic expectations, disillusionment, and a bleak outlook on life following UGHE's development. Their lack of interaction with UGHE students and staff led to general lack of awareness of UGHE's goals, a sense of isolation, and ill-feelings in relation to UGHE's development in Butaro. This is consistent with what is commonly described in community development literature (Chesoh, 2009). Butaro residents described their current encounters with UGHE by making a critical distinction between what migration literature deems "mundane interaction" and more meaningful social integration (Matarrita-Cascante, 2017). Our findings support literature which notes that mundane encounters limited to business interactions, no matter how frequent, are less likely to make locals feel a sense of community with new migrants. Instead, locals and new migrants must continually engage on more personal levels so that they can begin to see beyond their perceived differences (Matarrita-Cascante \& Stocks, 2013; Matarrita-Cascante, 2017). Since UGHE aims to be a global university that educates students of diverse origins and social-economic backgrounds, the image of "elitism" will probably persist. Efforts to better interact with and inform local residents, however, can help to improve overall community awareness, perceptions, and satisfaction with UGHE's Butaro campus. Emphasizing UGHE's role in local capacity building and informing local residents 
of UGHE scholarship opportunities and support for students within Rwanda and surrounding regions can help bridge perceived social divides between UGHE and Butaro community.

For Butaro residents, meaningful interactions include encounters with UGHE at social activities. Interactions like the monthly Community Laboring Saturday (Umuganda), sports events, and church gatherings create opportunities for deeper communication, resource sharing, cultural exchange, and trust development. The more UGHE interacts with the local community, the more approachable and less "foreign" or "other" the students and staff appear to Butaro residents, laying the foundation for mutual understanding.

Perhaps an additional and mutual barrier to desired social integration is language (MatarritaCascante \& Stocks, 2013). In a predominantly Kinyarwanda-speaking area, non-Rwandese UGHE staff and students may be hesitant to regularly interact with the local community and vice versa. UGHE might consider initiatives for "language exchange" as an avenue for meaningful interaction and enhanced communication.

Residents remind us that building successful partnerships requires $\mathrm{HEls}$ to willingly immerse themselves within the local community to: better understand the community's present needs and future aims; allow the local community to become more aware of their mission; and include the community at each stage of the development process (Fourie, 2003; Matarrita-Cascante \& Stocks, 2013). The FGDs themselves seemed to elevate local residents from beneficiaries of UGHE to stakeholders. Countering a common "I plan, you participate" mentality, UGHE's interest in community members' thoughts gave community members a sense of level footing with the university (Bandesha \& Litva, 2005). Butaro residents overwhelmingly expressed a desire to actively contribute to UGHE's development, progress, and initiatives. Participants described an ideal alliance where UGHE and the surrounding community work together to achieve improved quality of life. In line with literary findings, this dialogue enabled clarifications on the intended roles of UGHE and local community members and appeased disappointments stemming from miscommunication and confusion (Heenan, 2004). Continued involvement of the local community in this manner remains a critical first step for UGHE's, or other HEls', social integration and can optimize success in its future community engagement endeavors.

\section{a) Limitations}

Similar to most qualitative studies, information collected has limited generalizability to the wider population, especially when perceptions are highly personal and dependent on time and context. We could not eliminate respondent bias as some participants were recommended by local leaders; although snowball sampling was kept at a minimum and local leaders who referred participants were not present to hear participant responses during FGDs. Language was definitely a challenge to the study, despite the assistance of qualified data collectors and translators.

\section{Conclusion and Recommendations}

Although relocated residents mention challenges in adjusting to new ways of life, the study results suggested a general sense of pride and excitement concerning establishment of UGHE's Butaro campus. Findings highlight future opportunities for collaboration and growth. Specifically, Butaro residents expressed interest in health education, incomegenerating initiatives, local employment, and general investments in Butaro's overall economic growth and development.

Findings also revealed areas in which UGHE has already progressed in creating a lasting and formidable bond with the community. Student and staff engagement in social activities such as monthly Community Laboring Saturday, church services, and a UGHE vs. Butaro Community soccer match have fostered a positive image of UGHE within the community and were cited as essential ways of opening lines of communication among UGHE and the surrounding community.

Despite these successes, there were areas that required improvement. Sustaining intentional and continuous meaningful interactions with community members is essential. Communication channels to improve awareness of UGHE within the community, especially about the university's investment in local goods and services should be established. UGHE's subsequent community engagement efforts can enhance UGHE's position as an exemplary institution within the growing realm of rural-based education and university engagement in the advancement of global health.

\section{a) Recommendations}

The formation of an advisory committee comprised of community members could create a platform for respective parties to discuss each other's concerns and needs and establish means of collaboration to achieve growth and development within Butaro. Regular communication can help minimize unrealistic expectations and disappointment concerning UGHE's mission and purpose within Butaro. Sustained regular social interaction and development of other community initiatives catering to Butaro community needs can solidify UGHE's relationship with the community. Effort from UGHE students and staff to learn Kinyarwanda and also to teach English may also help to mitigate social barriers and strengthen communication. 
In line with UGHE's mission to "build the next generation of global health professionals," UGHE can begin to empower Butaro's youth and young children by collaborating with existing schools in the sector to create educational programs or initiatives concerning behavioral change activities. Such initiatives can also address local residents' desire for UGHE students to serve as mentors for local youth. UGHE may consider establishing a "Butaro Scholarship" scheme to support qualified students originating from Butaro in pursuing a medical degree. This could enhance the Butaro community's sense of ownership toward UGHE while refining local residents' ideas of the students UGHE educates. A similar study on Butaro community perceptions should be conducted within the coming years to monitor the longer term impact of UGHE on the Butaro community.

\section{b) UGHE's responses to the study results}

This study aimed to expand UGHE's understanding of the Butaro community's perceptions and expectations of the university in order to inform UGHE's community engagement initiatives. Despite the university's mission to deliver equitable and quality education to all, the modern campus inevitably portrayed the image of "eliteness" to the rural community. UGHE is the first and only zero-tuition medical school in Rwanda and all students in the medical program are Rwandans. However, the findings of this study showed the community viewed UGHE as an "unaffordable" institution only catering to foreigners. The university also has intentionally hired as many community members as possible and purchased most of the daily consumables from the local community. Such actions, however, were not visible to the community as indicated in this study. One major impetus behind this research project was to collect such information while the university-community relationship was still at its early stage to allow corrective actions.

In light of these findings, UGHE has developed a series of community engagement events. The university staff and students continue to engage in the monthly Community Labor Saturday. Formal after school tutorial programs were established between UGHE and community high schools with the aim of enhancing high school students' academic performance. UGHE also provides English courses to adult learners to assist their English language ability. The university has regularly invited community members to visit the campus. Events included sports and recreational activities, campus tours for Butaro residents, as well as informational sessions for high school students about higher education opportunities. Intentional communications were made by UGHE to ensure the community has accurate information about the university. A formal Community Engagement and Development Department was formed at the university to coordinate such activities. An advisory board including community members is being formed as another step to actively seek input from the community. More programs aimed at vocational skills development are in university plans. Another similar study will be conducted in the future in order to evaluate changes in perception.

Research ethics

The study was approved by the Institutional Review Board (IRB) of UGHE and by Butaro Sector leaders.

\section{Acknowledgements}

We thank: Butaro community members; Executive Secretary, Egide Ndayisaba; Eurade Ntakiyisumba and Vanessa Amani; Dr. Michelle Budwitz, Dr. Akiiki, Dr. Sylvia, Dr. Marissa Mika, Dr. Nolwazi; and all who supported this study.

\section{References Références Referencias}

1. Bandesha, G., \& Litva, A. (2005). Perceptions of community participation and health gain in a community project for the South Asian population: A qualitative study. Journal of Public Health, 27(3), 241-245.https://doi.org/10.1093/pubmed/fdi044

2. Binagwaho, A., Kyamanywa, P., Farmer, P. E., Nuthulaganti, T., Umubyeyi, B., Nyemazi, J. P.,... \& Ngirabega, J. D. D. (2013). The human resources for health program in Rwanda-a new partnership. New England Journal of Medicine, 369(21), 20542059.

3. Cancedda, C., Cotton, P., Shema, J., Rulisa, S., Riviello, R., Adams, L. V.,... \& Mumena, C. (2018). Health professional training and capacity strengthening through international academic partnerships: The first five years of the Human Resources for Health Program in Rwanda. International journal of health policy and management, 7(11), 1024.

4. Chesoh, S. (2009). Community Perception, Satisfaction and Participation toward Power Plant Development in Southernmost of Thailand. Power, 84-88.

5. Council on Higher Education (CHE) 2004. South African Higher Education in the first decade of democracy. Pretoria: Council on Higher Education

6. Crane, J. (2011). Scrambling for Africa? Universities and global health. The Lancet, 377(9775), 13881390. https://doi.org/10.1016/S0140-6736(10)6192 0-4

7. CUGH. (2019). Mission \&amp; Background. Retrieved July 15, 2019, from https://www.cu gh.org/about

8. Fine, P. (2019). The darker side of development: Good intentions, negative consequences. FHI 360. Retrieved from https://degrees.fhi360.org/2019/ 
02/the-darker-side-of-development-good-intentionsnegative-consequences/

9. Fourie, M. (2003). Beyond the ivory tower: servicelearning for sustainable community development. South African Journal of Higher Education, 17(1), 3138. https://doi.org/10.4314/sajhe.v17i1.25189.

10. Heenan, D. (2004). A partnership approach to health promotion: a case study from Northern Ireland. Health Promotion International, 19 (1), 105113. https://doi.org/10.1093/heapro/dah111

11. Kolars, J. C., Cahill, K., Donkor, P., Kaaya, E., Lawson, A., Serwadda, D., \& Sewankambo, N. K. (2012). Perspective: Partnering for medical education in Sub-Saharan Africa: Seeking the evidence for effective collaborations. Academic Medicine, 87(2), 216-220. https://doi.org/10.109 7/ACM.0b013e31823ede39.

12. Luvalo, L. M. (2014). The role of higher education in social transformation and rural development. Mediterranean Journal of Social Sciences, 5(23), 1206-1212. https://doi.org/10.5901/mjss.2014. v5n23 p1206.

13. Matarrita-Cascante, D., \& Stocks, G. (2013). Amenity migration to the global south: Implications for community development. Geoforum, 49 (December 2017), 91-102. https://doi.org/10.101 6/j. geoforum.2013.06.004.

14. Matarrita-Cascante, D. (2017). Moving the amenity migration literature forward: Understanding community-level factors associated with positive outcomes after amenity-driven change. Journal of Rural Studies, 53(December), 26-34. https://doi. org/10.1016/j.jrurstud.2017.05.004

15. Mtawa, N. N., Fongwa, S. N., \& Wangenge-ouma, G. (2016). The scholarship of university-community engagement : Interrogating Boyer's model, 1-20.

16. Ndayisaba, E. (2019, July 11). Personal interview.

17. Taché., S., Kaaya, E., Omer, S., Mkony, C. A., Lyamuya, E., Pallangyo, K.,... Mac Farlane, S. B. (2008). University partnership to address the shortage of healthcare professionals in Africa.

18. Global Public Health, 3(2), 137-148. https://doi.o $\mathrm{rg} / 10.1080 / 17441690701766486$.

19. THE REPUBLIC OF RWANDA. (n.d.). Retrieved fromhttp://www.statistics.gov.rw.

20. Thompson, A. F. (2014). The Role of Higher Education in Rural Community Development.

21. UGHE. (2019). About. Retrieved July 15, 2019, from https://ughe.org/about

\section{Appendix}

Focus Group Discussion Guides

Butaro Town Residents/ Local Leaders

1. What is your understanding of UGHE?

a. Prompt: From your point of view, what is the purpose of UGHE? What do you know about UGHE?
2. What has been your interaction so far with UGHE?

a. Prompt: Have you had any form of interaction with students or staff members? This can be outside of UGHEs campus. Was your experience positive or negative?

3. What was life like before the construction of UGHE began?

4. What is life like now since the opening of UGHE?

5. Considering that UGHE is not the first new development in your community, how do you feel about PIH/ Inshuti Mu Buzima's other recent developments?

a. For example, how has your experience been with Butaro Hospital?

6. Is the community the same? Is the community different? How so?

7. Given that UGHE is a permanent entity in Butaro, what do you think life will be like moving forward?

a. Prompt: Do you think there will be any changes like...new roads, businesses, new people etc. ?

8. How would you describe your ideal relationship with UGHE? How could UGHE work with the community?

9. What can the community contribute to UGHE?

10. Is there anything else you would like to share that has not been covered in this discussion?

\section{Local Staff}

1. What is your understanding of UGHE?

a. Prompt: From your point of view, what is the purpose of UGHE? What do you know about UGHE?

2. How did you find out about employment opportunities at UGHE or with contract companies at UGHE?

3. How would you describe your experiences working at UGHE so far? Are there any specific things that could be done to improve your work experiences?

4. How would you describe your interactions with students and staff?

5. Given that UGHE is a permanent entity in Butaro, what do you think life will be like moving forward?

6. Do you think there may be any changes to...employment opportunities, educational resources etc.?

7. Would you recommend your friends or family to work at UGHE?

8. Is there anything else you would like to share that has not been covered in this discussion?

\section{Displaced Residents}

1. What is your understanding of UGHE?

a. Prompt: From your point of view, what is the purpose of UGHE? What do you know about UGHE?

2. How did you learn about UGHE?

3. How has your day-to-day life changed since the establishment of UGHE?

4. How do you find your new housing/ community? 
5. After relocating, have you interacted with the campus community?

a. Prompt: This can include experiences outside of campus. How were your experiences?

6. How would you describe your ideal relationship with UGHE?

7. Given that UGHE is a permanent entity in Butaro, what do you think life will be like moving forward? 